\section{HYOSCIN IN INSANITY.}

BY THOMAS DRAPES, M.B.,

Resident Medical Superintendent of the District Asylum, Enniscorthy.

Ir is now some two years since Dr. Mitchell Bruce, in an article in the Practitioner, drew attention to the value of byoscin as a cerebral sedative. That so powerful a remedy has as yet come but little into general use in this country is probably due to the fact that it has constantly been confounded with hyoscyamineas evidenced by a correspondence in the JourNaL last year-a drug which, though isomeric with both hyoscin and atropine, has quite distinct therapeutic effects from either. Many have abandoned the use of hyoscyamine on account of the dangerous symptoms which have been observed to result from its action, and, being under the erroneous impression that the two drugs were identical, have refrained from the tise of hyoscin.

In what follows I shall confine myself to the delineation of the one distinctive action of the drug, which places it in quite a unique position as regards others of a similar class, namely, that of a safe, certain, and rapid cerebral sedative, unattended in the vast majority of instances by any unpleasant results. It is incomparably superior to the older sedatives, such as morphine and chloral, and none of the newer ones, in my opinion, approach it in value as a remedy for controlling paroxysms of furious excitement and turbulent maniacal outbreaks. The following cases will illustrate its action:

CASE r.-Male, J. R., aged 26; acute mania ; excitement day and night for some weeks, with sleeplessness, notwithstanding sedatives. On August 24th last, at 4 P.M., injected ${ }_{1}^{1} \frac{1}{50}$ gr. of hyoscin and put him to bed; no effect; at 10 P.M. To $\frac{2}{0}$ gr. injected, after which he slept five hours. 25th. s $^{1} \mathrm{gr}$. injected; three hours sleep. 27th. No hyoscin; passed a sleepless night. The drug was given on several other occasions with good results, the largest dose being $x^{1}$, gr., followed by five hours' sleep.

CASE II.-Female, C. F., aged 47; chronic mania, with periodic outbreaks of violence. During one of these, after having been for three nights turbulent and excited, I visited her in single room at 10 P.M. Found her standing on the floor, vociferating loudly, threatening everyone who came near her. While held by attendants, ro $\mathrm{l}$ gr. of hyoscin was injected. In ten minutes she was perfectly quiet and slept well that night; kept quiet for four nights; on the fifth again very noisy ; s' gr. injected with similar results.

CASE Irr.-Female, M. W., aged 36; paroxysms of violence, during which she uses most abusive and foul language for a whole night together. In one such attack, when at its acme, I

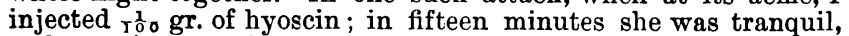
and remained so for several nights, sleeping some hours each night.

Case IV.-Male, J. H., aged 45; acute mania, sleeplessness, hallucinations, violence, refusal to eat; on opening his door on morning round, he stepped out naked in the corridor, with expression of dismay and limbs trembling; would not lie down; had taken no breakfast, and had been shouting and vociferating all morring. Injected ${ }_{\mathrm{I}}^{\frac{1}{6}} \mathrm{gr}$. of hyoscin. He was asleep in fifteen minutes, and on waking drank a quart of milk and egg and did not refuse food after.

CASE v.-Female, A. K., aged 49. Acute case of recurrent insanity, resembling most acute delirious mania in the first part of its course. Had been in asylum six years previously, when she got a quantity of chloral, laudanum, and morphine before sleep was produced. Present attack of one week's duration; violent, with suicidal impulses; refusal of food. At 12 o'clock on night of admission I found her lying across her bed with half her body on the floor, eyes staring and muddy, looking like a woman blinddrunk. Broad awake, but could not be got to utter a word. Pulse 112. Took five attendants to undress her, as she is a large heavy woman, and struggled violently. 10th. Condition unchanged, ate nothing. At 4 P.M. gave her, with great difficulty and in spite of most furious resistance, about three-quarters of a pint of milk and egg with œsophageal tube. 11th. Has not slept since admission. Looking very wild and moaning, but no articulate word. One pint and a half of fluid got down with tube under same violent resistance as before. The attendants were nearly ex-

2 Condensed from a paper read at the quarterly meeting of the MedicoPsycholugical Association in Dublin. hausted at the close of the administration. At 3 P.M. I injected qu $^{1}$ gr. of hyoscin. She soon fell asleep, and on waking drank voluntarily a pint of fluid, and spoke to attendant. At 10 P.M. I could hardly believe she was the same woman. She spoke quite rationally, remembered being here before, and said she knew her head (mind) was very bad. She then began moaning; I $^{\frac{1}{3} \sigma} \mathrm{gr}$. injected, and she slept about five hours ; then began moaning again, with occasional shout; passed her urine about the floor up to this. 12th. Took food herself : Pulse 100. In evening ró gr. of hyoscin; slept till 5 A.M. Allowed up. On 15th pulse had $\operatorname{come}$ down to 68 , and she went out walking. Recovery uninterrupted and rapid. The effect of the drug in this case was almost startling.

CASE VI.-As this case exhibits, in what may be called a typical manner, the tranquilising effects of hyoscin, I give it with a little more detail. Female, A. P., aged 58. Chronic mania, with paroxysms of excitement and violence, during which she kicks, bites, and strikes, if she gets the opportunity. On December 22nd she was in seclusion for this reason, where she kept talking incessantly at the top of her voice, pouring forth volleys of abuse, etc. At 10.23 A.M. $\frac{1}{3}$ gr. byoscin injected. 10.32 A.M. Voice subdued; talking in a low conversational tone, raising voice occasionally, but not to full extent. 10.35 A.M. Silence, broken by low fragmentary utterances. 10.38 A.ur. Absolute silence for some minutes, after which she talked a little in a low voice. At 10.45 A.M. I opened her door, and found her half lying on bed, looking a little languid. Pulse 88. Mouth a little dry, but probably due to continuous talking. She spoke quite rationally, asked me the time, complained of lightness of her head. I got her to lie down without any difficulty an! settle for sleep. Half an hour after she was perfectly quiet, and soon fell asleep, and remained so the entire afternoon, and did not again become excited for that occasion.

The psychical effect in this case was remarkable, and it is by no means a solitary instance, showing, I think, that the drug has, to a certain degree, a direct calmative influence on ideational disturbance, apart from its sleep-producing properties. The contrast, after a twenty minutes' interval, between the loudly vociferative and blasphemous tirade and the quiet subdued converse which ensued was sufficiently striking to warrant some such inference.

The foregoing cases, which might be considerably multiplied from my notebooks, sufficiently indicate the value of the drug. Its uniformity of action is one striking characteristic, and control of excitement, clamour, or violence, may be confidently anticipated from its administration. This it is which justifies the use of the term "certain," which I hare applied to it. As to its rapidity of action, I think the instances adduced prove this to demonstration, ten to twenty minutes usually sufficing to induce tranquillity. And as to safety, I can only say that I have not as yet seen any symptoms follow its use, such as to cause the least anxiety.

Giddiness is occasionally, not often, complained of ; this more by women than men. It is the only subjective symptom I have been able to elicit. Patients have not complained of dryness of the mouth, which is so constant and distressing a symptom after the use of hyoscyamine and atropine. Free perspiration frequently occurs, wherein hyoscin also differs markedly from its isomeric alkaloids. The pupils become moderately dilated under its influence, and the pulse is generally reduced in frequency. I have not once seen any dangerous symptom arise. Hyoscyamine cannot be said to present such an innocuous record. I may add that I have used it merely as a hypnotic in cases of insomnia without excitement, and found it answer admirably. In fact I invariably carry it with me on my nightly round, and in most cases where I used to give a morphine injection, I now give hyoscin

As to mode of administration, having tried its effects when given by mouth and found them unsatisfactory, I now always give the drug hypodermically. The particular preparation I have used from the first was Ferris and Co.'s liq. hyoscin. hydrobrom. There are probably others equally reliable, but I mention the one of which I have had experience myself. The strength of this solution is 1 in 400 , but for subdivision of dose it is better to dilute this with an equal quantity of distilled water, 1 drachm of each at a time, as the dilute does not keep as well as the stronger solution; of this diluted solution, 1 in 800,5 minims represents I grain, a very safe average dose to commence with hypodermically. But this may be rapidly increased to 8 minims (I 10 $\mathrm{gr}$. ), or more, if found insufficient. 